\title{
Gene expression profiling in wild-type and metallothionein mutant fibroblast cell lines
}

\author{
ÁNGELA D ARMENDÁRIZ ${ }^{1}$, FELIPE OLIVARES ${ }^{2}$, RODRIGO PULGAR ${ }^{2}$, \\ ALEX LOGUINOV ${ }^{1}$, VERÓNICA CAMBIAZO ${ }^{2}$, CHRISTOPHER D VULPE $^{1}$ \\ and MAURICIO GONZÁLEZ²
}

\footnotetext{
${ }^{1}$ Department of Nutritional Science and Toxicology, University of California, Berkeley, Berkeley, CA 94720

${ }^{2}$ Laboratorio de Bioinformática y Expresión Génica. Instituto de Nutrición y Tecnología de los Alimentos, Universidad de Chile, Santiago, Santiago, Chile
}

\begin{abstract}
The role of metallothioneins (MT) in copper homeostasis is of great interest, as it appears to be partially responsible for the regulation of intracellular copper levels during adaptation to extracellular excess of the metal. To further investigate a possible role of MTs in copper metabolism, a genomics approach was utilized to evaluate the role of MT on gene expression. Microarray analysis was used to examine the effects of copper overload in fibroblast cells from normal and MT I and II double knock-out mice (MT-/-). As a first step, we compared genes that were significantly upregulated in wild-type and MT-/- cells exposed to copper. Even though wild-type and mutant cells are undistinguishable in terms of their morphological features and rates of growth, our results show that MT-/- cells do not respond with induction of typical markers of cellular stress under copper excess conditions, as observed in the wild-type cell line, suggesting that the transcription initiation rate or the mRNA stability of stress genes is affected when there is an alteration in the copper store capacity. The functional classification of other up-regulated genes in both cell lines indicates that a large proportion ( $>80 \%$ ) belong to two major categories: 1) metabolism; and 2) cellular physiological processes, suggesting that at the transcriptional level copper overload induces the expression of genes associated with diverse molecular functions. These results open the possibility to understand how copper homeostasis is being coordinated with other metabolic pathways.
\end{abstract}

Key terms: copper homeostasis, metallothionein, microarray

\section{INTRODUCTION}

Copper is an essential nutrient that is a structural part in some proteins and part of the electron transfer system in many redoxenzymes involved in processes such as respiration, iron metabolism, and neurotransmitter biosynthesis (Uauy et al., 1999). Although essential metals are normally present in trace amounts in the cell, their levels can increase following environmental or nutritional changes. Metal overload can be toxic to the cell, causing a range of effects and leading to cell death when concentrations are extremely high (Pulido and Parrish, 2003; Oteíza et al.,
2004; Leonard et al., 2004). To avoid metal-induced toxicity, most organisms have developed several cellular mechanisms of protection. Three general mechanisms, which typically work in combination for effective detoxification, include: reduction of metal uptake; enhanced metal export; and metal sequestration mechanisms (Dameron and Harrison, 1998). The third mechanism, the intracellular chelation or sequestration of metals into less reactive complexes or organelles to limit their toxicity, is a commonly used mechanism. In mammalian systems, excess metals, in particular 
copper, are partially detoxified by sequestration in the metal-binding metallothioneins (Dameron and Harrison, 1998; Bremner and Beattie, 1990; Nordberg, 1989).

Metallothioneins (MTs) are a class of low molecular weight, intracellular and cysteine-rich proteins that have high affinity for metal ions (Cousins, 1983; Park et al., 2001; Coyle et al., 2002). MT gene sequences are highly conserved in a wide range of species from bacteria to humans, which is a suggestive feature of a protein with a high biological importance. MTs have unique structural characteristics for their potent metal-binding and redox capabilities. Although the members of this family were discovered nearly 40 years ago, a primary role has not been identified, and new functions continue to be discovered (Palmiter, 1998). Currently, MTs are known to be involved in metal ion homeostasis and detoxification, protection against oxidative damage, cell proliferation and apoptosis, chemoresistance, and radiotherapy resistance (Palmiter, 1998; Coyle et al., 2002). MT expression has been implicated as a transient response to any form of stress or injury and may provide cytoprotective action. Four major MT isoforms - MT I, MT II, MT III, and MT IV - have been identified in mammals (Coyle et al., 2002; Theocharis et al., 2003). MT I and MT II are the two major forms in mammals; they are expressed in most tissues and stages of development. The analysis of mice with altered gene expression of MT I and II has enhanced our understanding of the multifaceted role of MT. MT I/II double knockout (MT-/-) mice demonstrated that MT expression is not essential for the normal development, growth, or reproductive capacity of these mice (Klaassen and Liu, 1998). These mutant mice and the cell lines derived from them have been used extensively in recent years to investigate the role of MT. Most results show that animals or cells lacking MT I/II are more sensitive to a wide range of stressors, such as oxidative stress; excess metals, such as cadmium, lead, copper and zinc; and infectious and inflammatory agents (Zheng et al., 1996; Kelly et al.,
1996; Kelly and Palmiter, 1996; Liu et al., 1999; Rojas and Klaassen, 1999; Liu et al., 2000; Qu et al., 2002).

The role of MT in copper homeostasis is of great interest, as it appears to be responsible for the regulation of intracellular copper levels during adaptation to extracellular copper excess. It has been shown that MT protects cells against elevated levels of extracellular copper (Freedman and Peisach, 1989; Kawai et al., 2000). As copper toxicity involves its ability to catalyze the generation of free radicals and/or to directly interact with essential biomolecules, copper sequestering by MT is of critical importance for cell protection. Besides serving to detoxify excess copper, MT may play a role in normal copper metabolism, although currently this role is unknown.

In a recent study, we demonstrated notable changes in copper metabolism in a MT I/II mutant (MT-/-) fibroblast cell line (Tapia et al., 2004). We showed that MT-/cells were more sensitive to increasing amounts of copper in the media than wildtype cells exposed to the same concentrations. Also, by measuring intracellular copper levels and by conducting uptake studies, we demonstrated that although both mutant and wild type cell lines accumulate copper upon treatment with copper, the MT-/- cells took up considerably less copper than the wild-type cells. Interestingly, in this condition, we observed that mutant cells died with lower intracellular copper content (2-fold lower), supporting a protective role for MT in the response to $\mathrm{Cu}$ excess. These results permitted us to deduce that copper toxicity does not rely on the increased amount of intracellular metal, but rather on the cellular ability to manage the metal, therefore, in the molecular interactions that copper establishes inside the cell. In this context, we showed that in the absence of MTs, the capacity of copper to induce gene expression of MT, SOD1 and its chaperone, Ccs, is lost. This observation could partially explain the increased vulnerability of MT null cells to lower intracellular copper concentrations and suggest that MT may be a modulator of gene expression (Tapia et al., 2004). 
In the present study, we show that wildtype and mutant cells are undistinguishable in terms of their morphological features and rates of growth and define a minimal copper dose that provided a significant increment in the copper content of both cell lines. Using these conditions, we applied a genomic approach to further investigate a possible role of MTs as part of a pathway that induces gene expression in response to copper. As a first step in exploring the effects that loss of this important copper sequestering protein had on gene expression, we carried out microarray analysis to identify genes significantly upregulated in wild-type and MT-/- cells exposed to an excess of copper and to determine which genes failed to be upregulated in MT mutant cells as compared to wild-type cells. The results of these analyses are presented here.

\section{MATERIALS AND METHODS}

\section{Cell lines and treatments}

The cell lines used in the present study correspond to wild type and MT I/II mutant (MT-/-) fibroblasts obtained by trypsinization of mouse embryos from day 11 of gestation and immortalized with SV40 virus (Kelly and Palmiter, 1996). The mutation in the MT-/- cell line was achieved by introducing translation stop sequences in the MT I and II exons, thus the mutant cell line expresses a modified MT mRNA and fails to express the protein (Tapia et al., 2004). Culture and treatment conditions have been described (Tapia et al., 2004). Briefly, fibroblasts were incubated at $37^{\circ} \mathrm{C}$ in a $5 \% \mathrm{CO} 2$ atmosphere and grown in plastic cell culture flasks (Nalge Nunc Int. Corp. IL, USA) containing Dulbecco's modification of Eagle's medium (DMEM) and 10\% fetal bovine serum (SFB). The concentrations of elements in this basal culture medium were $\mathrm{Cu}$ 0.4, Fe 2.7 and Zn 3.8 $\mu \mathrm{M}$ (González et al., 1999). For all treatments, copper was supplemented in the cultured medium as $\mathrm{Cu}$-His complex (1: 10 molar ratio) at the concentrations and times specified in the figure 2 legend. After the treatment, cells were processed for $\mathrm{Cu}, \mathrm{Zn}$ and $\mathrm{Fe}$ quantification. To evaluate cell viability under copper treatment, cells were grown in 24-well cell culture plates (Nunc) and relative survival of the treated cells was evaluated using 3-[4,5-dimethylthiazol-2y1]-2,5- diphenyltetrazolium bromide (MTT, Sigma) reduction assays as described (Denizot and Lang, 1986). The viability percentage was determined by comparing the measurements of the average absorbance from a given treatment group with that obtained from a reference sample of the same cell line treated for identical time with a control medium $(100 \%$ of viability). To determine the population doubling time, the cell number was counted under a microscope daily for at least 5 days using a hemocytometer and the trypan blue $(0.4 \%)$ exclusion method.

\section{Immunofluorescence staining}

Cells were washed three times with phosphate buffered saline (PBS), fixed for $10 \mathrm{~min}$ in $3.7 \%$ formaldehyde in PBS and permeabilized for 5 min with $0.2 \%$ triton $\mathrm{X}$ 100 in $3.7 \%$ formaldehyde. The fixed cells were re-hydrated with Tris buffered saline (TBS) and incubated for $1 \mathrm{~h}$ in blocking solution (3\% BSA in TBS). To evidence the organization of microfilaments, cells were incubated with anti-actin monoclonal antibody (SIGMA) diluted 1: 500 in 3\% BSA-TBS, and with the secondary antibody, FITC-conjugated rabbit-antimouse IgG (Rockland, Gilbertsville, PA), at a 1: 250 dilution in 3\% BSA-TBS. Cells were incubated with primary or secondary antibodies for $1 \mathrm{~h}$ at $37^{\circ} \mathrm{C}$. Finally, cells were rinsed in $\mathrm{TBS}$, mounted in $\mathrm{DABCO} /$ mowiol, and examined with a epifluorescence microscope $(40 \times$ objective, Nikon, Labophot-2, Tokyo, Japan). As controls, experiments were performed in which the first or second antibodies were omitted.

\section{$C u, F e$ and $\mathrm{Zn}$ quantification}

For total metal content quantification, cells were processed as previously described 
(González et al., 1999; Tapia et al., 2004). Briefly, cells $(2-4 \times 105)$ at $80 \%$ of confluence were disrupted in concentrated suprapure nitric acid (Merck) in a vortex and diluted with distilled deionized water. Samples were digested at $60^{\circ} \mathrm{C}$ overnight. The $\mathrm{Cu}$ determination was made by means of a graphite furnace atomic adsorption spectrophotometer (AAS, Perkin Elmer, SIMMA 6100). Calibration was against a standard curve made from dilutions of a $\mathrm{Cu}$, $\mathrm{Fe}$ or $\mathrm{Zn}$ standard ( $\mathrm{J} \mathrm{T}$ Baker) and the sample values were normalized to the total protein content.

\section{RNA isolation and cDNA labeling}

Total RNA was extracted from wild-type and MT-/- mutant cell lines in the same passage number maintained under basal cell culture conditions or exposed to $100 \mu \mathrm{M}$ $\mathrm{Cu}$-His for $48 \mathrm{~h}$ using RNAWIZ reagent (Ambion). The indirect, or amino-allyl labeling protocol was adapted from the microarrays.org website (http: // microarrays.org/protocols.html). $25 \mu \mathrm{g}$ total RNA and $5 \mu \mathrm{g}$ of oligo dT were brought to a total volume of $15.5 \mu \mathrm{l}$ and denatured for $10 \mathrm{~min}$ at $70^{\circ} \mathrm{C}$, then chilled on ice. An equal volume of reverse transcription reaction mix (2X first strand buffer, $20 \mathrm{mM}$ DTT, 95 U SuperScript II, $1 \mathrm{mM}$ dATP, 1 mM dGTP, 1 mM dCTP, 0.6 mM dTTP, and $0.4 \mathrm{mM}$ amino-allyl-dUTP) was added, and the reaction was incubated at $42^{\circ} \mathrm{C}$ overnight. The reaction was denatured by bringing it to $0.2 \mathrm{~N} \mathrm{NaOH}, 0.1 \mathrm{M}$ EDTA and incubating at $65^{\circ} \mathrm{C}$ for $15 \mathrm{~min}$, and neutralized by the addition of Tris- $\mathrm{Cl} \mathrm{pH}$ 7.4 to a final concentration of $0.3 \mathrm{M}$. The buffer was removed, and the cDNA was concentrated by filtering through a Microcon-30. After drying in a speed vac, the cDNA was resuspended in $4.5 \mu \mathrm{l}$ sterile water. The cDNA then was coupled to either monofunctional $\mathrm{Cy} 3$ or Cy 5 dye (Amersham Pharmacia) in $0.1 \mathrm{M}$ sodium bicarbonate buffer, $\mathrm{pH} 9.0$, at room temperature, in the dark, for $1 \mathrm{~h}$. The two dye reactions were purified separately with a Qia-Quick PCR purification kit (Qiagen). cDNA quantity and dye incorporation of each probe was assessed with a scanning spectrophotometer. The two dye probes were then combined and concentrated in a speed vac to a volume of 15-20 $\mu \mathrm{l}$. SSC and SDS were added to a final concentration of $2.6 \mathrm{X}$ and $0.2 \%$ respectively. The probes were denatured for $2 \mathrm{~min}$ at $95^{\circ} \mathrm{C}$, allowed to cool, then placed on a post-processed microarray and incubated overnight at $60^{\circ} \mathrm{C}$. After hybridization, the microarray slides were washed at room temperature for $5 \mathrm{~min}$ in $1 \mathrm{XSSC}$, and $0.05 \% \mathrm{SDS}$, then for 2 min in $0.2 X S S C$, and finally for $2 \mathrm{~min}$ in $0.1 \mathrm{XSSC}$, and then were spin dried. The microarrays were fabricated at the College of Natural Resources Genomics Facility (http: //genomics.cnr.berkeley.edu). These arrays contained 11,000 mouse cDNAs, randomly selected from the Brain Molecular Anatomy Project, BMAP (http: // trans.nih.gov/bmap/) library (Research Genetics). Genes contained in this library are derived from 10 different adult mouse brain regions as well as spinal cord and retina.

\section{Data analysis}

Microarray slides were scanned on an ArrayWorx (Applied Precision) scanner. The intensity of hybridization values was determined using Genepix Pro 3.0 (Axon) image analysis software for each probe in both channels (Cy5- 695 nm, Cy3- 595 nm). All intensity values are backgroundsubtracted, normalized by median of channel intensity (to account for dye bias), and $\log$ (base 2)- transformed. A recently developed method to identify differentially expressed genes between two mRNA samples, based on identification of outliers as candidate differentially expressed genes (Loguinov, et al., 2004), was used. The majority of data points after appropriate normalization lie in the vicinity of the line of equivalence in the scatter plot of $\log 2(\mathrm{Cy} 5)$ vs. $\log 2(\mathrm{Cy} 3)$ intensity values. Other data points, outliers, lie outside the vicinity of the line of equivalence and are considered to be data points of greatest interest, since they correspond to genes having noticeably different hybridization intensities. Robust scatter plot smoothers to quantify and take into account the distortion 
of the data set by heteroscedasticity (if any) were applied. Outliers from this analysis are considered to represent candidate differentially expressed genes. A confidence ( $p$ value) for each outlier is assigned by calculating simultaneous prediction confidence intervals (Loguinov et al., 2004). Sequence homology searches were done against mouse/rodent sequence databases, using the WU-BLAST 2.0 program at MouseBLAST (http: // mouseblast.informatics.jax.org/). Differentially expressed genes were grouped according to their biological process using the Gene Ontology Classifications found at the Mouse Genome Informatics Website (http: // www.informatics.jax.org/) and at the Gene Ontology Consortium Website (http: // www.geneontology.org/).

\section{RESULTS}

The absence of MT does not modify the cellular morphology or the rate of growth of mutant fibroblasts

In order to assess whether the absence of MT affects the growth of mutant cells, the morphology and the rate of growth of both cell lines were compared. When wild-type and MT-/- cells were maintained in basal culture medium $(0.4 \mu \mathrm{M} \mathrm{Cu})$, they showed a monolayer growth pattern with similar sizes and morphological features (Fig. 1, upper panels), which is clearly observed by the organization of the microfilament network (Fig. 1, lower panels). After copper treatment, we did not detect changes in the morphological features of both cell lines (data not shown). In the absence of copper

\section{Wild-type}
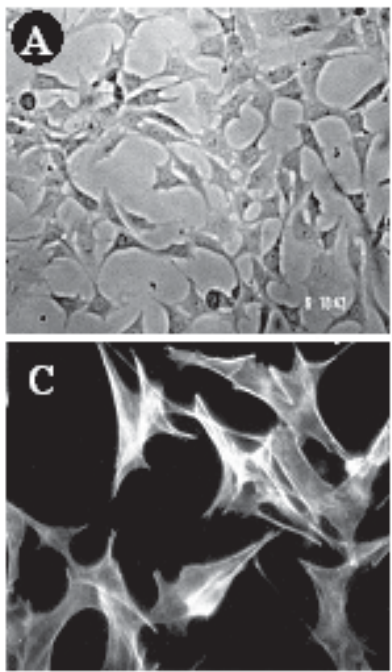

MT(-/-)
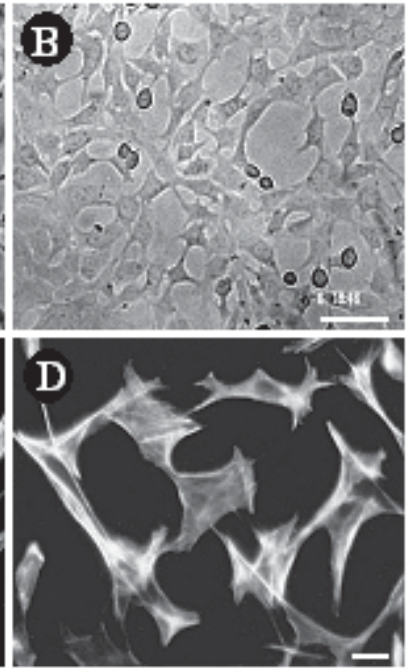

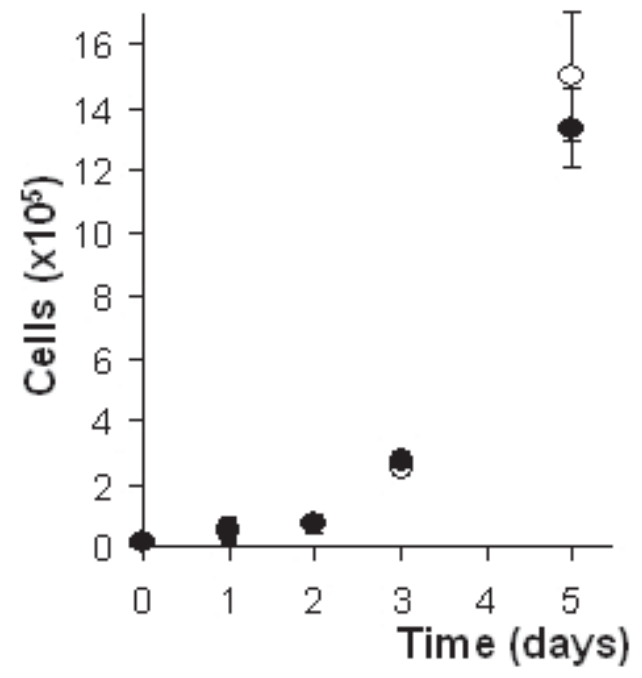

Figure 1. Comparison of morphological features and rate of growth between wild-type and MT-/- cells.

Microphotographs show the morphology of sub-confluent cultures of wild-type (A) and MT-/- (B) cells. Cells were analyzed using phase-contrast microscopy. Bar $=10 \mu \mathrm{m}$. Representative images of actin distribution patterns are shown for wild-type (C) and MT-/- (D). Microfilaments were stained as described in Materials and Methods. To determine the rate of growth, cells were cultured under basal conditions, and the total number of cells was quantified using trypan blue every day for 5 days. The experiment was performed in triplicate, and results are expressed as mean \pm SD. 
supplement, the growth curve of wild-type and MT-/- cells were nearly identical (Fig. $1)$. Once seeded, cells displayed a phase of slow growth (0-2 days) followed by of a phase of fast growth (3-5 days) until reaching confluence ( $>90 \%$ at day 5$)$ at this time; their growth was inhibited by cellular contact. The deviation observed at day 5 was not statistically significant. From these curves, we calculated a population doubling time of $22 \mathrm{~h}$. These results indicate that morphological features and proliferation rate of cells was unaffected by the absence of MT.

\section{Differential $C u$ content and viability in wild type and MT-/- cells exposed to $\mathrm{Cu}$-His}

Wild-type and MT-/- cell lines growing in standard culture conditions showed no significant differences in the $\mathrm{Cu}, \mathrm{Fe}$ and $\mathrm{Zn}$ content. When fibroblasts were exposed for $48 \mathrm{~h}$ with rising graded copper concentrations (up to $250 \mu \mathrm{M} \mathrm{Cu}$-His), intracellular $\mathrm{Cu}$ content increased in both cell lines, but in wild-type fibroblasts, rose significantly more than in MT-/- fibroblasts (Fig. 2). Regarding the other trace metals, results show that $\mathrm{Zn}$ content remains unaffected and Fe content decreased about 2 -fold in both cell lines. Thus, $\mathrm{Cu}$ exposure primarily affected intracellular $\mathrm{Cu}$ content, but also affected the $\mathrm{Fe}$ content to a lesser degree, providing further evidence for their metabolic interaction. Since we have shown that viability of wild-type and MT-/- cells exposed to an excess of $\mathrm{Cu}$ decreased in a time-dependent manner (Tapia et al., 2004), we selected a time of $48 \mathrm{hrs}$ of coppertreatment for our gene expression analysis. The chosen extracellular copper concentration was $100 \mu \mathrm{M}$, a minimal dose of copper that generated a significant difference on intracellular $\mathrm{Cu}$ content between wild-type and MT-/- cells (Fig. 2). Under these conditions, cell viability of wild-type and MT-/- lines was $95.2 \%$ and $77.6 \%$, respectively.

\section{Microarray experiment design}

Gene expression in copper-treated wild type and MT-/- cells was compared to their untreated counterparts. RNA from four different cell conditions was used: 1) untreated wild-type cells; 2) $100 \mu \mathrm{M}$ copper-treated wild-type cells; 3) untreated MT mutant cells; and 4) $100 \mu \mathrm{M}$ coppertreated MT mutant cells. All copper-treated cells were treated for 48 hours prior to harvesting; the untreated cells were collected simultaneously. Wild-type was compared to copper-treated wild-type cells in four experiments; and MT-/- was compared to copper-treated MT-/- cells in four experiments. Although a total of eight microarray experiments were carried out, six were successfully completed and analyzed. Even though the repeated experiments were technical and not biological replicates, dye swaps were incorporated into some of them. The RNA used for each cell line was isolated on the same day; however, the microarray experiments (reverse transcription, labeling, and hybridizations) were done on different days.

\section{Detection of differentially expressed genes}

We identified differentially expressed genes from each hybridization using the outlier identification method described by Loguinov et al. (2004). We were interested in those genes, which were significantly upregulated in copper-treated cells (WT, $100 \mu \mathrm{M} \mathrm{Cu}$ and MT-/-, $100 \mu \mathrm{M} \mathrm{Cu})$ as compared to untreated cells (WT and MT-/-). As shown in figure 3 , the majority of the data points lie in the vicinity of a robust linear regression line of the scatter plot of $\log 2(\mathrm{Cy} 5) \mathrm{v} / \mathrm{s}$ $\log 2(\mathrm{Cy} 3)$ intensity values. These data points correspond to genes with similar hybridization intensity values in the two samples, while other data points lie outside the scatter plots and correspond to genes having noticeably different values of intensity. We determined $\log 2(\mathrm{Cy} 5 / \mathrm{Cy} 3) /$ $\mathrm{s}(\mathrm{I})$ to estimate statistical significance ( $\mathrm{p}$ values) for every gene to be a candidate for differential expression. $\mathrm{s}(\mathrm{I})$ is a robust scale estimator dependent on intensity and is used to build simultaneous prediction intervals for graphical representation of genes outside the intervals that are most likely outliers. Robust scatter plot smoothers are used to account 


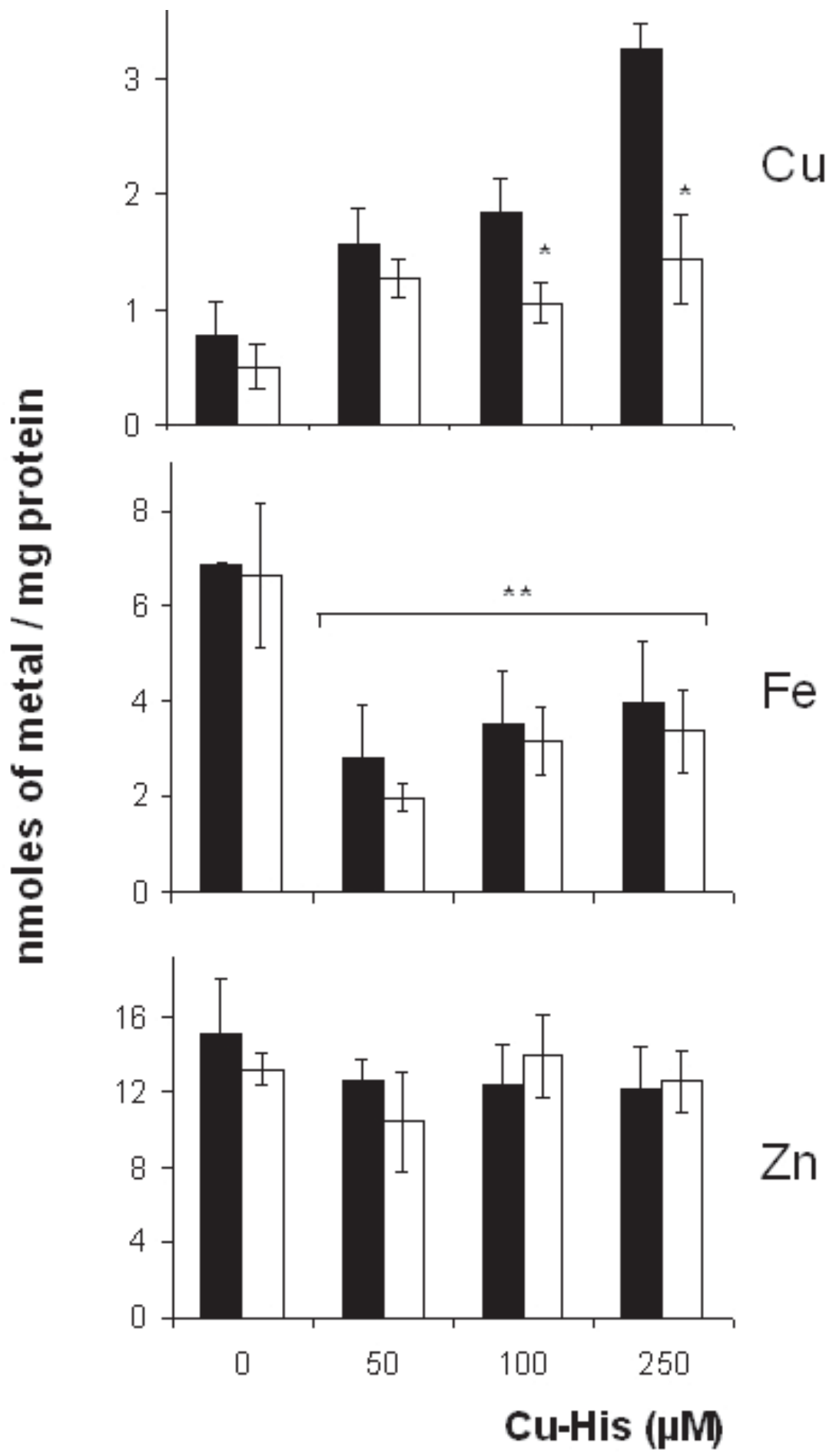

Figure 2. $\mathrm{Cu}, \mathrm{Fe}$ and $\mathrm{Zn}$ content in wild-type and mutant MT-/- cells exposed to $\mathrm{Cu}-\mathrm{His}$.

Total metal content of wild-type cells and MT mutants determined by AAS in response to graded concentrations of $\mathrm{Cu}-\mathrm{His}$ at $48 \mathrm{~h}$. Filled bars correspond to wild-type cells and open bars to MT-/cells. Each bar represents the mean value of triplicate experiments and corresponding standard deviation. ANOVA analysis for both cell types demonstrated a significant effect induced by $\mathrm{Cu}$ exposure. (*) denotes significant difference as compared to wild-type cells, $\mathrm{p}<0.05$; $(* *)$ denotes level of exposure in which the concentration effect was significant, $\mathrm{p}<0.05$. 

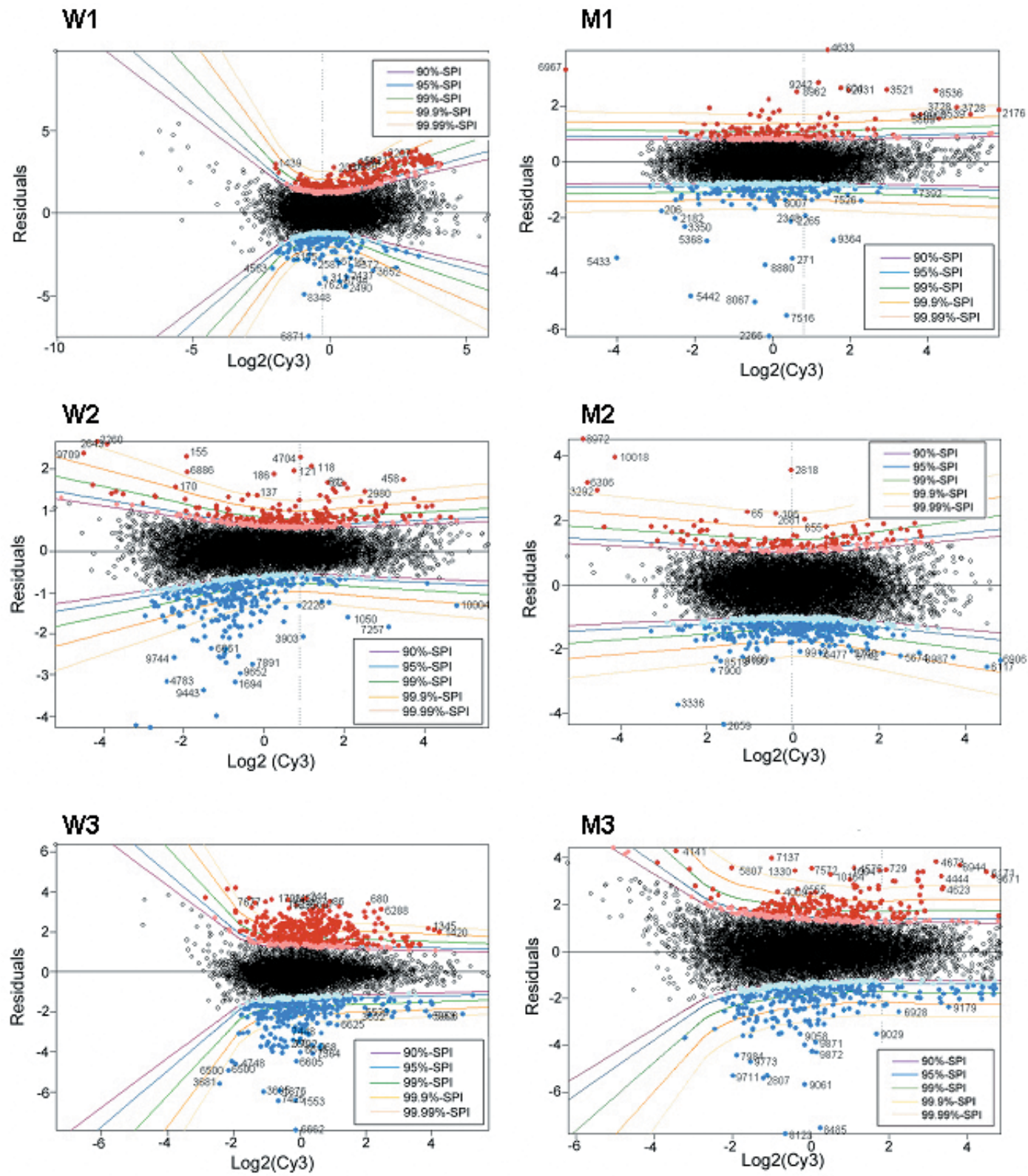

Figure 3. Detection of differentially expressed genes.

Simultaneous prediction intervals (SPI) for the three WT,100 $\mu \mathrm{M} \mathrm{Cu} \mathrm{v/s} \mathrm{WT} \mathrm{and} \mathrm{the} \mathrm{three} \mathrm{MT-/-,}$ $100 \mu \mathrm{M} \mathrm{Cu}$ v/s. MT-/- data sets (W1, W2 and W3 and M1, M2, and M3, respectively) are shown. For each experiment, the robust and resistant linear regression line (black) was calculated using the S-plus MM-estimator. Then the data was normalized by linear regression making slope $=1$, intercept $=0$ and subtracting the linear trend to deal with residuals that are $\log 2(\mathrm{Cy} 5 / \mathrm{Cy} 3)$. SPIs are corrected with the S-plus scatter plot smoother supsmu applied to absolute residuals, $\log 2(\mathrm{Cy} 5 /$ Cy3)I, to reveal the dependence of residual variance on intensity values. The supsmu-based SPIs assume residual heteroscedasticity. Pink (cyan) points lie in the interval between the upper (lower) 90\% and 95\% SPIs. Red (blue) points lie above the upper (lower) 95\% SPI. Black points lie below the upper and lower 90\% SPI. The 90\%, 95\%, 99\%, 99.9\% and 99.99\% SPIs are shown. The vertical dotted line marks the location of the minima of the empirical hyperbolas. Therefore, red/ pink, blue/cyan and black points represent candidate upregulated, candidate downregulated and unchanged genes respectively. 
for heteroscedasticity (variation in residual variance with intensity) in each data set. Red outliers on the top of the graph represent candidate up-regulated genes while the outlying spots of blue color, on the bottom, represent candidate down regulated genes. We considered data outliers with p-value 0.05 as candidate differentially expressed genes. We compared the candidate genes of each experiment and selected genes (i.e., outliers with a p-value < 0.05 ) identified in two or more repeat hybridizations as likely differentially expressed genes. In the WT, $100 \mu \mathrm{M} \mathrm{Cu} \mathrm{v/s} \mathrm{WT} \mathrm{experiments,} \mathrm{there} \mathrm{were}$ 104 up-regulated genes in at least two of the three experiments, 31 of them were ESTs that had not yet been annotated. In the MT-/-, $100 \mu \mathrm{M} \mathrm{Cu} \mathrm{v/s} \mathrm{MT-/-} \mathrm{experiments} \mathrm{there}$ were 133 up-regulated genes, 37 of them corresponded to un-annotated genes. For each of the annotated genes, tables 1,2 and 3 display the name, symbol and their GeneBank accession number. Genes upregulated in: a) both WT and MT -/- cells; b) only WT cells; and c) only MT -/- cells are listed in tables 1,2 and 3, respectively.

\section{Functional classification of differentially expressed genes}

Functional annotation of the differentially expressed genes was performed aiming to discover features characteristic to the sets of genes up-regulated in $100 \mu \mathrm{M}$ coppertreated WT and MT-/- cells. We classified genes from tables 1 and 2 according to their biological process using the GO database. GO provides a controlled vocabulary organized in a hierarchical fashion that can be applied to describe gene products from eukaryotic organisms regarding molecular function, biological process, and cellular component. GO terms for the biological process ontology were found for approximately $60 \%$ of the genes differentially expressed in $100 \mu \mathrm{M}$ coppertreated WT and MT-/- cells. Pie graphs illustrating the biological process of genes up-regulated in $100 \mu \mathrm{M}$ copper-treated WT and MT-/- cells are shown in figure 4A and B. Approximately $50 \%$ of the genes with known biological function are involved in cellular physiological processes. This group includes genes that play roles in signal transduction, transport, cytoskeleton organization, and regulation of transcription and translation. The next larger category $(\approx 30 \%)$ corresponds to genes involved in metabolism. Within this category, $36 \%$ of the genes up-regulated in copper treated WT cells are involved in protein modification, whereas in copper-treated MT-/- cells the greatest percentage (36\%) correspond to genes that play roles in protein biosynthesis. $15 \%$ of the genes upregulated in copper-treated WT cells are involved in response to a stimulus (highlighted in grey, Tables 1 and 2), 75\% of them correspond to genes with functions in stress response to temperature. In copper-treated MT-/- cells, there is a smaller portion of genes $(9 \%)$ in this category (highlighted in grey, Tables 1 and 3 ), and only $25 \%$ of them correspond to those involved in response to temperature.

\section{DISCUSSION}

The role of MT has been extensively studied, however it remains elusive. Part of the reason is that MT has been implicated in a variety of physiological processes, such as metal storage, metal detoxification, oxidative scavenging, cell proliferation, and inflammatory response (Palmiter, 1998; Coyle et al., 2002).

In copper homeostasis, MT plays a role in the regulation of intracellular copper levels during adaptation to excess copper. It has been well demonstrated that MT protects cells against high levels of copper by sequestering excess amounts of the metal (Palmiter et al., 1992; Quaife et al., 1994; Haq et al., 2003). In addition to serving to detoxify excess copper, MT may play a role in normal copper metabolism. In a previous work (Tapia et al., 2004), we took advantage of the simultaneous generation of two fibroblast cell lines from littermate mouse fetuses (Kelly and Palmiter, 1996): one expresses MT, while the other expresses modified mRNA isoforms of MT I and II that are not able to be translated into proteins. In these cell lines, we evaluated the role of $\mathrm{MT}$ in $\mathrm{Cu}$ metabolism, monitoring a 
wide range of parameters such as viability, $\mathrm{Cu}$ content, $\mathrm{Cu}$ uptake and efflux, subcellular localization, and the expression of MT and some other $\mathrm{Cu}$ metabolismrelated genes. Our results indicated that, within the physiological range, the role of MT is to provide a safe storage compartment for $\mathrm{Cu}$. As a consequence of this function, at supra-physiological levels of $\mathrm{Cu}$ exposure MT has a role in detoxification. Additionally, MT is a modulator of gene expression, since in its absence, exposure to high $\mathrm{Cu}$ concentrations failed to induce the expression of MT and other $\mathrm{Cu}$ metabolismrelated genes such as those encoding SOD1 and Ccs, suggesting a second mechanism by which MT may contribute to cellular resistance to $\mathrm{Cu}$ exposure.

In the present work, we further analyzed the effects that loss of MT had on gene expression using a genomic approach. In this study, we utilized cDNA microarray technology to evaluate the effects of copper excess on global gene expression in wildtype and MT-/- cells. In the microarray experiments, we compared transcripts from a wild-type to copper-treated wild-type cells, and from a MT-/- to copper-treated MT-/- cells. We were interested in determining genes that were upregulated in the two cell lines as a result of handling excess of copper and identifying which genes failed to be upregulated in MT null cells as compared to wild-type cells. We hypothesized that, by comparing the effects of copper overload in a normal cell to copper overload in a Mt deficient cell, insight into MT's normal role in copper homeostasis could be gained. We were interested in the differences/similarities in the handling of excess copper between the two cell types to understand what pathways are affected only in the MT deficient cells, as this might indicate areas where MT is required. Any similarities in affected pathways would likely indicate areas where MT is not important or uninvolved.

It is generally accepted that copper in excess, due to its redox cycling capacity, can give rise to the generation of reactive oxygen species capable of producing oxidative stress (Halliwell and Gutteridge, 1984) and that MT protects the cell from this oxidative stress by sequestering excess copper (Dameron and Harrison, 1998; Kaway et al., 2000). Thus, we expected that stress would be high in MT-/- cells exposed to excess levels of copper. When we analyzed the genes up-regulated in $100 \mu \mathrm{M}$ copper-treated wild-type cells, we found that seven genes encoding heat shock proteins were induced. These heat shock proteins - Hspb1, Hspca, Hsp105, Hspa1a, Hspa8, Dnajb6, and Dnajc10 - are widely conserved and overexpressed at high temperatures or other stress conditions (Lindquist and Craig, 1988). Moreover, catalase (cat) and superoxide dismutase $3(\operatorname{Sod} 3)$ were also upregulated in the $100 \mu \mathrm{M}$ copper-treated cells, as compared to untreated wild-type cells. Induction of these genes generally indicates that the cell is undergoing stress (Whitley et al., 1999; Nollen and Morimoto, 2002; Bauer and Bauer, 2002; Otterbein et al., 2003). Surprisingly, only three of the stress-related genes (Hspa1a, Dnaja1, and Hspd1) were induced in $100 \mu \mathrm{M}$ coppertreated MT-/- cells, indicating that the MT-/cells are not responding with induction of typical markers of cellular stress under copper excess conditions, as compared to the wild-type cell line. In a previous work, using the same experimental approach, we utilized fibroblast cell lines from two mutant mice, C57BL/6-Atp7a (Mobr) and C57BL/6-Atp7a (Modap), to evaluate the effects of chronic copper overload on cellular gene expression (Armendáriz et al., 2004). These cells showed a severe loss-of-function in the ATP7a gene with a cellular defect in copper efflux that leads to high levels of intracellular copper accumulation in standard culture media. Similar results to those obtained in MT-/- cells exposed to copper were observed for both ATP7a mutant cell lines, showing no differential expression of oxidative stress genes, besides the upregulation of MT. When taken together, these results suggest that the transcriptional regulation of stress genes is affected when the machinery that controls copper homeostasis is altered. It is possible that: 1) the cells are unable to sense stress; or 2) the untreated MT-/- cells are already stressed, thus explaining why there is no difference as compared to copper loaded MT-/- cells. 

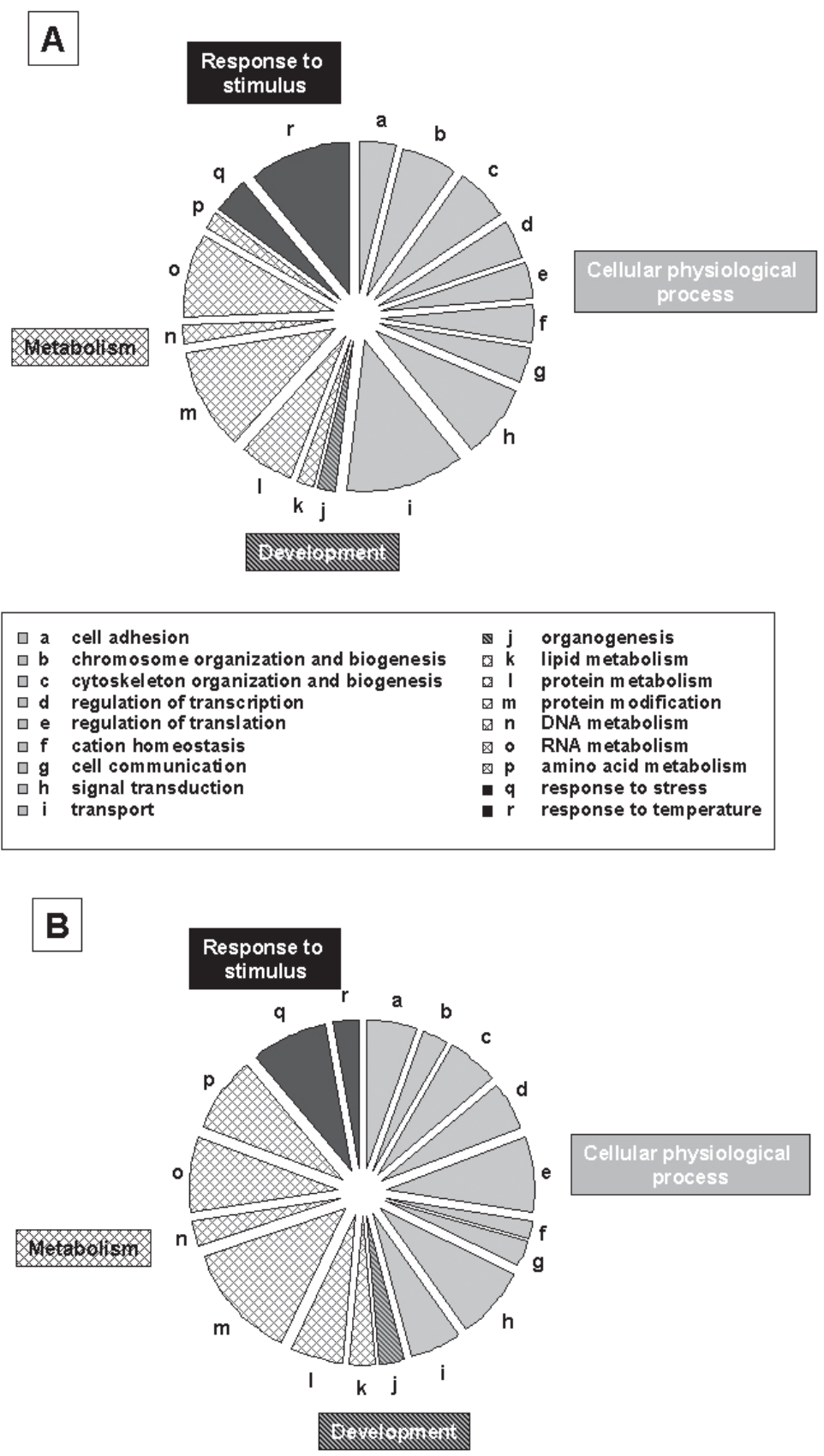

\begin{tabular}{|c|c|c|c|c|}
\hline ㅁ & a & cell adhesion & $\Delta \mathbf{j}$ & organogenesis \\
\hline$\square$ & b & chrom os ome organization and biogenesis & 这 & nucleotide metabolism \\
\hline$\square$ & c & cytos keleton organization and biogenes is & I & protein m etabolism \\
\hline$\square$ & d & regulation of transcription & 日 m & protein m odification \\
\hline$\square$ & e & regulation of translation & r $n$ & DNA metabolism \\
\hline$\square$ & f & cation homeostas is & घ 0 & RNA metabolism \\
\hline$\square$ & g & cell comm unication & $\nabla p$ & protein biosynthesis \\
\hline$\square$ & h & signal transduction & - 9 & response to stress \\
\hline$\square$ & $\mathbf{i}$ & transport & ar $r$ & response to temperature \\
\hline
\end{tabular}

Figure 4. Functional classifications of up-regulated genes.

Up-regulated genes in $100 \mu \mathrm{M}$ copper-treated WT (A) and MT-/- cells (B) with known functions were grouped according to their biological process in three major categories: Cellular physiological process, Metabolism, and Response to stimulus. Subcategories are labeled a to r. 
TABLE 1

Genes commonly up-regulated in $100 \mu \mathrm{M}$ copper-treated WT and MT-/- cells ( $\mathrm{p}$-value $<0.05$ )

\begin{tabular}{|c|c|c|}
\hline GenBank & Gene name & Symbol \\
\hline AI854152 & adenomatosis polyposis coli & Apc \\
\hline AI837758 & capping protein, alpha 2 & Capza2 \\
\hline AI839184 & DNA segment, Chr 3, MJeffers 1 & D3Jfr1 \\
\hline AI839363 & eukaryotic translation initiation factor 3 , subunit 6 & Eif3s6 \\
\hline AI843263 & eukaryotic translation initiation factor 5 & Eif5 \\
\hline AI841289 & heat shock protein $1 \mathrm{~A}$ & Hspa1a \\
\hline AI844131 & heterogeneous nuclear ribonucleoprotein A2/B1 & Hnrpa2b1 \\
\hline AI850620 & matrin 3 & Matr3 \\
\hline AI480893 & metallothionein 2 & Mt2 \\
\hline AI846930 & progesterone receptor membrane component 1 & Pgrmc1 \\
\hline AI843656 & protein kinase $\mathrm{C}$, delta & Prkcd \\
\hline AI838689 & protein tyrosine phosphatase $4 \mathrm{a} 2$ & Ptp4a2 \\
\hline AI837314 & RAB7, member RAS oncogene family & RAB7 \\
\hline AI845039 & RIKEN cDNA 1110038008 gene & 1110038O08Rik \\
\hline AI839993 & scavenger receptor class $\mathrm{B}$, member 2 & Scarb2 \\
\hline AI840197 & secreted acidic cysteine rich glycoprotein & Sparc \\
\hline AI841699 & ubiquitin A-52 residue ribosomal protein fusion product 1 & Uba52 \\
\hline AI836012 & t-complex-associated-testis-expressed 1-like & Tcte 11 \\
\hline AI838607 & thrombospondin 1 & Thbs 1 \\
\hline AI847817 & tight junction protein 1 & Tjp1 \\
\hline AI836699 & zinc finger, A20 domain containing 2 & $\mathrm{Za} 20 \mathrm{~d} 2$ \\
\hline
\end{tabular}


TABLE 2

Genes up-regulated in $100 \mu \mathrm{M}$ copper-treated WT cells ( $\mathrm{p}$-value < 0.05)

\begin{tabular}{|c|c|c|}
\hline GenBank & Gene name & Symbol \\
\hline AI840802 & 5'-3' exoribonuclease 2 & Xrn2 \\
\hline AI839327 & activating transcription factor 7 interacting protein & Atf7ip \\
\hline AI854581 & advanced glycosylation end product-specific receptor & Ager \\
\hline AI838490 & amyloid beta (A4) precursor-like protein 1 & Aplp1 \\
\hline AI854771 & angiomotin & Amot \\
\hline AI849453 & arginyl-tRNA synthetase & Rars \\
\hline AI835672 & ATPase type 13A2 [Mus musculus] & Atp13a2 \\
\hline AI844698 & ATP-binding cassette, sub-family A, member 2 (Abca2) & Abca2 \\
\hline AI527414 & catalase & Cat \\
\hline AI835756 & dendritic cell protein GA17 & Ga17 \\
\hline AI836002 & DNA segment, Chr 13, Wayne State University 64, expressed & D13Wsu64e \\
\hline AI842025 & DNA segment, Chr 5, Brigham \& Women's Genetics 0860 expressed & D5Bwg0860e \\
\hline AI845673 & DnaJ (Hsp40) homolog, subfamily B, member 6 & Dnajb6 \\
\hline AI838060 & DnaJ (Hsp40) homolog, subfamily C, member 10 & Dnajc 10 \\
\hline AI837696 & erythrocyte protein band 4.1 -like 2 & Epb4.112 \\
\hline AI196520 & ferritin heavy chain & Fth \\
\hline AI852695 & Growth hormone inducible transmembrane protein & Ghitm \\
\hline W30103 & heat shock protein 1 & Hspb1 \\
\hline AI836122 & heat shock protein 1 , alpha & Hspca \\
\hline AI838486 & heat shock protein 105 & Hsp 105 \\
\hline AI841358 & heat shock protein 8 & Hspa8 \\
\hline AA265447 & hemochromatosis & Hfe \\
\hline AI851595 & heterogeneous nuclear ribonucleoprotein A3 & Hnrpa3 \\
\hline AI836554 & high density lipoprotein-binding protein & Hdlbp \\
\hline AI851942 & kelch repeat and $\mathrm{BTB}(\mathrm{POZ})$ domain containing 2 & Kbtbd2 \\
\hline AI847525 & kinesin family member 5B & Kif5b \\
\hline AI840212 & leukocyte receptor cluster, member 5 & Leng 5 \\
\hline AI839417 & moesin & Msn \\
\hline AI842649 & myosin, light polypeptide 9 , regulatory & My19 \\
\hline AI847531 & platelet-activating factor acetylhydrolase, isoform $1 \mathrm{~b}$, beta 1 subunit & Pafah1b1 \\
\hline AI847890 & proteolipid protein & $\mathrm{Plp}$ \\
\hline AI847455 & RAB10, member RAS oncogene family & Rab10 \\
\hline AI850275 & Rap2 interacting protein & Rap2ip \\
\hline AI850616 & RIKEN cDNA $1700064 \mathrm{~K} 09$ gene & 1700064K09Rik \\
\hline AI851276 & RIKEN cDNA $2210401 \mathrm{~K} 01$ gene & 2210401K01Rik \\
\hline AI849320 & RIKEN cDNA 2310037P21 gene & 2310037P21Rik \\
\hline AI845633 & RIKEN cDNA 6130401J04 gene & 6130401J04Rik \\
\hline AI836603 & RIKEN cDNA A430005L14 gene & A430005L14Rik \\
\hline AI851553 & RIKEN cDNA E430034L04 gene & E430034L04Rik \\
\hline AI839936 & ring finger protein 13 & Rnf13 \\
\hline AI854671 & SET translocation & Set \\
\hline AI843695 & solute carrier family 37 (glycerol-3-phosphate transporter), member 3 & Slc37a3 \\
\hline AI317380 & superoxide dismutase 3 , extracellular & Sod3 \\
\hline AI834833 & transducin (beta)-like $1 \mathrm{X}$-linked receptor 1 & Tbl1xr1 \\
\hline AI853375 & transformed mouse $3 \mathrm{~T} 3$ cell double minute 2 & $\mathrm{Mdm} 2$ \\
\hline AI848382 & ubiquitin specific protease 1 & Usp1 \\
\hline AI839048 & vesicular inhibitory amino acid transporter & Viaat \\
\hline AI852047 & zinc finger, $\mathrm{CCHC}$ domain containing 6 & Zcchc6 \\
\hline
\end{tabular}


TABLE 3

Genes up-regulated in $100 \mu \mathrm{M}$ copper-treated MT-/- cells (p-value < 0.05)

\begin{tabular}{|c|c|c|}
\hline GenBank & Gene name & Symbol \\
\hline AI845042 & annexin A5 & Anxa5 \\
\hline AI837594 & ATP synthase, $\mathrm{H}+$ transporting, mitochondrial F0 complex ,b, isoform 1 & Atp5f1 \\
\hline AI848681 & ATPase, $\mathrm{H}+$ transporting, lysosomal accessory protein 2 & Atp6ap2 \\
\hline AI836191 & ATP-binding cassette, sub-family $\mathrm{C}$, member 5 & Abcc5 \\
\hline AI848245 & beta-2 microglobulin & $\mathrm{B} 2 \mathrm{~m}$ \\
\hline AI854022 & carnitine deficiency-associated gene expressed in ventricle & Cdv3 \\
\hline AI847251 & casein kinase 1 , alpha 1 & Csnk1a1 \\
\hline AI845078 & CDC42 small effector 1 & Cdc42se 1 \\
\hline AI844682 & cell division cycle 42 homolog (S. cerevisiae) & $\mathrm{Cdc} 42$ \\
\hline AI841451 & cut-like 1 (Drosophila) & Cutl1 \\
\hline AI850430 & death-associated kinase 3 & Dapk3 \\
\hline AI841974 & DNA segment, Chr 11, ERATO Doi 99, expressed & D11Ertd99e \\
\hline AI837235 & DnaJ (Hsp40) homolog, subfamily A, member 1 & Dnaja1 \\
\hline AI849475 & enhancer of polycomb homolog 1 (Drosophila) & Epc1 \\
\hline AI843451 & eukaryotic translation elongation factor 1 alpha 1 & Eef1a1 \\
\hline AI851493 & eukaryotic translation initiation factor 2 , subunit 2 (beta) & Eif $2 \mathrm{~s} 2$ \\
\hline AI836099 & eukaryotic translation initiation factor 4 , gamma 2 & Eif4g2 \\
\hline AI841804 & expressed in non-metastatic cells 1 & Nme1 \\
\hline AI847926 & golgi apparatus protein 1 & Glg1 \\
\hline AI838039 & heat shock protein 1 (chaperonin) & Hspd 1 \\
\hline AI841981 & hepatitis $B$ virus $x$ interacting protein & Hbxip \\
\hline AI843558 & heterogeneous nuclear ribonucleoprotein $\mathrm{K}$ & Hnrpk \\
\hline AI848331 & heterogeneous nuclear ribonucleoprotein $\mathrm{U}$ & Hnrpu \\
\hline AI836129 & high mobility group nucleosomal binding domain 2 & Hmgn2 \\
\hline AI850268 & methionine adenosyltransferase II, alpha & Mat2a \\
\hline AI853257 & mitochondrial ribosomal protein S33 & Mrps33 \\
\hline AI853143 & mortality factor 4 like 1 & Morf411 \\
\hline AI847934 & neurofilament, light polypeptide & Nefl \\
\hline AI848144 & neuron specific gene family member 2 & $\mathrm{Nsg} 2$ \\
\hline AI841664 & nucleosome assembly protein 1-like 1 & Nap111 \\
\hline AI838078 & nudix-type motif 9 & Nudt9 \\
\hline AI852884 & Phosphatidylinositol binding clathrin assembly protein & Picalm \\
\hline AI848346 & polyadenylate-binding protein-interacting protein 2 & Paip2 \\
\hline AI843948 & proteasome subunit, alpha type & Psma3, \\
\hline AI838874 & protein phosphatase $2 \mathrm{a}$, catalytic subunit, beta & Ppp2cb \\
\hline
\end{tabular}




\begin{tabular}{|c|c|c|}
\hline GenBank & Gene name & Symbol \\
\hline AI838463 & RAS related protein $1 \mathrm{~b}$ & Rap1b \\
\hline AI849041 & Ras-like without CAAX 2 & Rit2 \\
\hline AI847923 & regulator of G-protein signaling 2 & Rgs2 \\
\hline AI844168 & reticulon 4 receptor & $\operatorname{Rtn} 4 \mathrm{r}$ \\
\hline AI845529 & ribonuclease P 40 subunit (human) & Rnasep1 \\
\hline AI851588 & ribosomal protein L23 & Rpl23 \\
\hline AI834863 & ribosomal protein L26 & Rpl26 \\
\hline AI841501 & ribosomal protein $\mathrm{S} 3 \mathrm{a}$ & Rps3a \\
\hline AI853900 & RIKEN cDNA 1110055L24 gene & 1110055L24Rik \\
\hline AI847909 & RIKEN cDNA 1700030A21 gene & 1700030A21Rik \\
\hline AI840191 & RIKEN cDNA 2210409B22 gene & 2210409B22Rik \\
\hline AI840046 & RIKEN cDNA 2310047D13 gene & 2310047D13Rik \\
\hline AI854255 & RIKEN cDNA $2410002 \mathrm{O} 22$ gene & 2410002O22Rik \\
\hline AI838261 & RIKEN cDNA 3110001 N18 gene & 3110001N18Rik, \\
\hline AI849886 & RIKEN cDNA 4631403P03 gene & 4631403P03Rik \\
\hline AI843449 & RIKEN cDNA $4921531 \mathrm{G} 14$ gene & G630041M05Rik \\
\hline AI835456 & RIKEN cDNA 5730454B08 gene & 5730454B08Rik \\
\hline AI835904 & RIKEN cDNA 5730470L24 gene & 5730470L24Rik \\
\hline AI849033 & RIKEN cDNA 7530403E16 gene & 7530403E16Rik \\
\hline AI850130 & RIKEN cDNA 8430420C20 gene & 8430420C20Rik \\
\hline AI842640 & RIKEN cDNA A730042J05 gene & A730042J05Rik \\
\hline AI853842 & RWD domain containing 1 & Rwdd 1 \\
\hline AI850227 & SECIS binding protein 2 & Secisbp2 \\
\hline AI847805 & secreted phosphoprotein 1 & Spp1 \\
\hline AI848364 & SMT3 suppressor of mif two 3 homolog 1 (yeast) & Ubl1 \\
\hline AI845086 & smu-1 suppressor of mec-8 and unc-52 homolog (C. elegans) & Smu-1 \\
\hline AI840676 & spectrin beta 2 & Spnb2 \\
\hline AI845051 & spectrin beta 3 & Spnb3 \\
\hline AI843287 & Tax 1 binding protein 1 & Tax $1 b p 1$ \\
\hline AI853152 & thymopoietin & Tmpo \\
\hline AI851197 & transcription factor 4 & Tcf4 \\
\hline AI849958 & transducin (beta)-like 3 & Tbl3 \\
\hline AI849063 & transforming growth factor beta 1 induced transcript 4 & Tgfb1i4 \\
\hline AI854679 & tumor differentially expressed 2 & Tde2 \\
\hline AI844401 & tumor protein D52 & Tpd52 \\
\hline AI845961 & ubiquitin-conjugating enzyme E2L 3 & Ube213, \\
\hline \multirow[t]{2}{*}{ AI854256 } & UDP-N-acetyl-alpha-D-galactosamine:polypeptide & Galnt 10 \\
\hline & $\mathrm{N}$-acetylgalactosaminyltransferase 10 & \\
\hline
\end{tabular}


It is relatively well established that MTdeficient cells are more sensitive (i.e., less viable) to excess copper; therefore, it seems counterintuitive that these cells did not show signs of increased stress. However, it is important to note that these MT-/- cells were shown by us (Tapia et al., 2004) to accumulate less copper when exposed to increasing levels of the metal. A similar phenomenon was seen in MT-deficient cells exposed to lead. In this study, lead-exposed cells were more sensitive to lead despite accumulating much less of the metal as compared to their wild-type counterparts (Qu et al., 2002). This might suggest that MT-/- cells are unable to sense the stress, and perhaps it is the lack of induction of the stress response pathways that make them more sensitive to these metals. This potential incapability to sense the stress might be related to impaired activation of the MTF-1 transcription factor, since the specific activation of MTF-1 requires, in addition to copper excess, a zinc-saturated MT (Zhang et al., 2003). MTF-1 is involved in several cellular responses, including oxidative stress, hypoxia, and amino acid starvation (Murphy et al., 1999), and its activation might be modulated by heat shock (Saydam et al., 2003), which place MTF-1 as an important component of the cross-talk between different anti-stress systems in the cell. The possibility that untreated MT-/cells are already stressed is consistent with their higher sensitivity to copper exposure as compared to wild-type cells, which has been observed in cell viability studies by us and others (Kelly and Palmiter, 1996; Tapia, 2004) and with the fact that in the absence of MT, cells are unable to store copper in a safe compartment (Tapia et al., 2004). In this scenario, we might assume a high level of expression of stress genes, even when cells are exposed to low extracellular copper. Therefore, we are unable to detect significant changes in the relative expression of stress genes; in order to clarify this point, it is necessary to perform a comparison between untreated wild-type and MT-/- cells. Moreover, we cannot rule out the option that the mechanisms to induce the expression of stress genes in MT-/- cells require a longer period of time to become activated, thus it will be interesting to perform serial timecourse microarray experiments to compare the gene profile in wild-type and MT-/- cell lines.

Among other genes up-regulated in 100 $\mu \mathrm{M}$ copper-treated wild-type cells, we found ferritin, an iron sequestering protein composed of 2 types of subunits - H (heavy chain) and L (light chain) - that play a key role in the maintenance of the intracellular iron balance (Torti and Torti, 2002). Although ferritin is known primarily for its critical role in cellular and organism iron homeostasis, it is unlikely that high iron levels are inducing ferritin, as intracellular iron levels in both the MT-/- and WT cells slightly decrease upon copper treatment (Fig. 2). There is evidence, however, that suggests that ferritin plays a role in protection against oxidative damage (Arosio and Levi, 2002). It has been shown that overexpression of the $\mathrm{H}$ subunit leads to a reduced production of reactive oxygen species (ROS) after exposure to hydrogen peroxide and that ferritin is subject to both transcriptional, as well as translational, regulation by oxidative stress (Tsuji et al., 2000; Orino et al., 2001). Further studies will be needed to understand the role of MT in the transcriptional regulation of ferritin in copper overload cells.

Another gene with potential roles in metal homeostasis is HFE, the hemochromatosis gene. Mutations in this gene cause progressive body iron overload, which leads to tissue damage and ultimately multiorgan failure (Drakesmith and Townsend, 2000; Parkkila et al., 2001). The function of HFE protein is unknown, but some evidence suggests that it acts together with beta2-microglobulin and transferrin receptor 1 to regulate iron uptake in the intestinal cells (Anderson and Powell, 2002). In the Caco 2 cell line, it was shown that HFE mRNA is induced by $\mathrm{Fe}$, but not by other metals $(\mathrm{Co}, \mathrm{Cu}$, and $\mathrm{Zn}$ ) (Han et al., 1999), and there is currently no evidence to suggest that it is induced by oxidative stress (Sánchez et al., 1998; Mura et al., 2004). As with ferritin, further studies are necessary to understand the significance of HFE induction in the copper-treated cells. 
A large proportion of genes $(>80 \%)$ upregulated in wild-type and MT-/- cells after copper exposure were classified into two major categories: 1) metabolism; and 2) cellular physiological processes. A similar distribution was reported by Armendáriz et al. (2004) for the two cell lines that accumulate copper due to a defect in copper export, suggesting that copper overload induces the expression of genes associated with diverse molecular function. Therefore, microarray analysis seems to be useful to compare the behavior of wild-type cells and cells with mutations in different components of $\mathrm{Cu}$ metabolism in response to fluctuations in $\mathrm{Cu}$ availability. We consider that the results obtained through these experiments provide experimental support to connect copper homeostasis with other metabolic pathways.

\section{ACKNOWLEDGEMENTS}

This work was supported by grants 1050235 and 1030618 from Fondecyt (to $\mathrm{VC}$ and $\mathrm{MG}$ ) and by grants from the International Copper Association, United States Department of Agriculture NRI 9900815 and a University of California Toxic Substance (to CDV) Research and Training Program traineeship (ADA).

\section{REFERENCES}

ANDERSON GJ, POWELL LW (2002) HFE and non-HFE hemochromatosis. Int J Hematol. 76: 203-207

ARMENDÁRIZ AD, GONZÁLEZ M, LOGUINOV AV, VULPE CD (2004) Gene expression profiling in chronic copper overload reveals upregulation of Prnp and App. Physiol Genomics. 20: 45-54

AROSIO P, LEVI S (2002) Ferritin, iron homeostasis, and oxidative damage. Free Radic Biol Med. 33: 457-463

BAUER M, BAUER I (2002) Heme oxygenase-1: Redox regulation and role in the hepatic response to oxidative stress. Antioxid Redox Signal. 4: 749-758

BREMNER I, BEATTIE JH (1990) Metallothionein and the trace minerals. Annu Rev Nutr. 10: 63-83

COUSINS RJ (1983) Metallothionein - Aspects related to copper and zinc metabolism. J Inherit Metab Dis. 6 Suppl 1: 15-21

COYLE P, PHILCOX JC, CAREY LC, ROFE AM (2002) Metallothionein: The multipurpose protein. Cell Mol Life Sci. 59: 627-647

DAMERON CT, HARRISON MD (1998) Mechanisms for protection against copper toxicity. Am J Clin Nutr. 67 5 Suppl: 1091S-1097S
DENIZOT F, LANG R (1986) Rapid colorimetric assay for cell growth and survival. Modifications to the tetrazolium dye procedure giving improved sensitivity and reliability. J. Immunol. Methods. 89: 271-277

DRAKESMITH H, TOWNSEND A (2000) The structure and function of HFE. Bioessays. 22: 595-598

FREEDMAN JH, PEISACH J (1989) Resistance of cultured hepatoma cells to copper toxicity. Purification and characterization of the hepatoma metallothionein. Biochem Biophys Acta. 992: 145-154

GONZÁLEZ M, TAPIA L, ALVARADO M, TORNERO JD, FERNÁNDEZ, R (1999) Intracellular determination of trace elements by total-reflection $\mathrm{X}$ ray fluorescence spectrometry in mammalian cultured cells. J Anal At Spectrom. 14: 885-888

HALLIWELL B, GUTTERIDGE JM (1984) Oxygen toxicity, oxygen radicals, transition metals and disease. Biochem J. 219: 1-14

HAN O, FLEET JC, WOOD RJ (1999) Reciprocal regulation of HFE and NNamp2 gene expression by iron in human intestinal cells. J Nutr. 129: 98-104

HAQ F, MAHONEY M, KOROPATNICK J (2003) Signaling events for metallothionein induction. Mutat Res. 533: 211-226

KAWAI K, LIU SX, TYURIN VA, TYURINA YY, BORISENKO GG, JIANG JF, ST CROIX CM, FABISIAK JP, PITT BR, KAGAN VE (2000) Antioxidant and antiapoptotic function of metallothioneins in HL-60 cells challenged with copper nitrilotriacetate. Chem Res Toxicol. 13: 1275-1286

KELLY EJ, PALMITER RD (1996) A murine model of Menkes disease reveals a physiological function of metallothionein. Nat Genet. 13: 219-222

KELLY EJ, QUAIFE CJ, FROELICK GJ, PALMITER RD (1996) Metallothionein I and II protect against zinc deficiency and zinc toxicity in mice. J Nutr. 126: 17821790

KLAASSEN CD, LIU J (1998) Metallothionein transgenic and knock-out mouse models in the study of cadmium toxicity. J Toxicol Sci. 23 Suppl 2: 97-102

LEONARD SS, BOWER JJ, SHI X (2004) Metal-induced toxicity, carcinogenesis, mechanisms and cellular responses. Mol Cell Biochem. 255: 3-10

LINDQUIST S, CRAIG E (1988) The heat-shock proteins. Annu. Rev. Genet. 22: 631- 677

LIU J, LIU Y, HARTLEY D, KLAASSEN CD, SHEHINJOHNSON SE, LUCAS A, COHEN SD (1999) Metallothionein-I/II knockout mice are sensitive to acetaminopheninduced hepatotoxicity. J Pharmacol Exp Ther. 289: 580-586

LIU Y, LIU J, HABEEBU SM, WAALKES MP, KLAASSEN CD (2000) Metallothionein- I/II null mice are sensitive to chronic oral cadmium-induced nephrotoxicity. Toxicol Sci. 57: 167-176

LOGUINOV AV, MIAN IS, VULPE CD (2004) Exploratory differential gene expression analysis in microarray experiments with no or limited replication. Genome Biol. 5: R18

MURA C, LE GAC G, JACOLOT S, FEREC C (2004) Transcriptional regulation of the human HFE gene indicates high liver expression and erythropoiesis coregulation. Faseb J. 18: 1922-1924

MURPHY BJ, ANDREWS GK, BITTEL D, DISCHER DJ, MCCUE J, GREEN CJ, YANOVSKY M, GIACCIA A, SUTHERLAND RM, LADEROUTE KR, WEBSTER KA (1999) Activation of metallothionein gene expression by hypoxia involves metal response elements and metal transcription factor-1. Cancer Res. 59: $1315-1322$

NOLLEN EA, MORIMOTO RI (2002) Chaperoning 
signaling pathways: molecular chaperones as stresssensing 'heat shock' proteins. J Cell Sci. 115: 28092816

NORDBERG GF (1989) Modulation of metal toxicity by metallothionein. Biol Trace Elem Res. 21: 131-135

ORINO K, LEHMAN L, TSUJI Y, AYAKI H, TORTI SV, TORTI FM (2001) Ferritin and the response to oxidative stress. Biochem J. 357: 241-247

OTEÍZA PI, MACKENZIE GG, VERSTRAETEN SV (2004) Metals in neurodegeneration: Involvement of oxidants and oxidant-sensitive transcription factors. Mol Aspects Med. 25: 103-115

OTTERBEIN LE, SOARES MP, YAMASHITA K, BACH FH (2003) Heme oxygenase: unleashing the protective properties of heme. Trends Immunol. 24: 449-455

PALMITER RD, FINDLEY SD, WHITMORE TE, DURNAM DM (1992) MT-III, a brainspecific member of the metallothionein gene family. Proc Natl Acad Sci U S A. 89: 6333-6337

PALMITER RD (1998) The elusive function of metallothioneins. Proc Natl Acad Sci U S A. 95: 84288430

PARK JD, LIU Y, KLAASSEN CD (2001) Protective effect of metallothionein against the toxicity of cadmium and other metals. Toxicology. 163: 93-100

PARKKILA S, NIEMELA O, BRITTON RS, FLEMING RE, WAHEED A, BACON BR, SLY WS (2001) Molecular aspects of iron absorption and HFE expression. Gastroenterology. 121: 1489-1496

PETRIS MJ, MERCER JF, CULVENOR JG, LOCKHART P, GLEESON PA, CAMAKARIS J (1996) Ligandregulated transport of the Menkes copper P-type ATPase efflux pump from the Golgi apparatus to the plasma membrane: A novel mechanism of regulated trafficking. Embo J. 15: 6084-6095

PULIDO MD, PARRISH AR (2003) Metal-induced apoptosis: Mechanisms. Mutat Res. 533: 227-241

QU W, DIWAN BA, LIU J, GOYER RA, DAWSON T, HORTON JL, CHERIAN MG, WAALKES MP (2002) The metallothionein-null phenotype is associated with heightened sensitivity to lead toxicity and an inability to form inclusion bodies. Am J Pathol. 160: 1047-1056

QUAIFE CJ, FINDLEY SD, ERICKSON JC, FROELICK GJ, KELLY EJ, ZAMBROWICZ BP, PALMITER RD (1994) Induction of a new metallothionein isoform (MT-IV) occurs during differentiation of stratified squamous epithelia. Biochemistry. 33: 7250-7259
ROJAS P, KLAASSEN CD (1999) Metallothionein-I and II knock-out mice are not more sensitive than control mice to 1-methyl-4-phenyl-1,2,3,6-tetrahydropyridine neurotoxicity. Neurosci Lett. 273: 113-116

SÁNCHEZ M, QUERALT R, BRUGUERA M, RODES J, OLIVA $\mathrm{R}$ (1998) Cloning, sequencing and characterization of the rat hereditary hemochromatosis promoter: comparison of the human, mouse and rat HFE promoter regions. Gene. 225: 77-87

SAYDAM N, STEINER F, GEORGIEV O, SCHAFFNER W (2003) Heat and heavy metal stress synergize to mediate transcriptional hyperactivation by metalresponsive transcription factor MTF-1. J Biol Chem. 278: 31879-31883

TAPIA L, GONZÁLEZ-AGÜERO M, CISTERNAS MF, SUAZO M, CAMBIAZO V, UAUY R, GONZÁLEZ M (2004) Metallothionein is crucial for safe intracellular copper storage and cell survival at normal and supraphysiological exposure levels. Biochem J. 378(Pt 2): 617-624

THEOCHARIS SE, MARGELI AP, KOUTSELINIS A (2003) Metallothionein: A multifunctional protein from toxicity to cancer. Int J Biol Markers. 18: 162-169

TORTI, FM TORTI SV (2002) Regulation of ferritin genes and protein. Blood. 99: 3505-3516

TSUJI Y, AYAKI H, WHITMAN SP, MORROW CS, TORTI SV, TORTI, FM (2000) Coordinate transcriptional and translational regulation of ferritin in response to oxidative stress. Mol Cell Biol. 20: 58185827

UAUY R, OLIVARES M, GONZÁLEZ M (1999) Essentiality of copper in humans. Am J Clin Nutr. 67: 952S-959S

WHITLEY D, GOLDBERG SP, JORDAN WD (1999) Heat shock proteins: A review of the molecular chaperones. J Vasc Surg. 29: 748-751

ZHANG B, GEORGIEV O, HAGMANN M, GUNES C, CRAMER M, FALLER P, VASAK M, SCHAFFNER W (2003) Activity of metal-responsive transcription factor 1 by toxic heavy metals and $\mathrm{H} 2 \mathrm{O} 2$ in vitro is modulated by metallothionein. Mol Cell Biol. 23: 8471-8845

ZHENG H, LIU J, LIU Y, KLAASSEN CD (1996) Hepatocytes from metallothionein-I and II knock-out mice are sensitive to cadmium- and tertbutylhydroperoxide-induced cytotoxicity. Toxicol Lett. 87: $139-145$ 